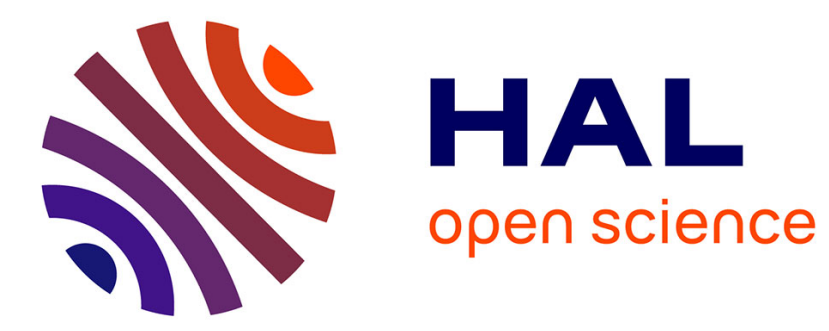

\title{
International graduate students' perceptions and interest in international careers
}

Nikos Bozionelos, Giorgos Bozionelos, Konstantinos Kostopoulos, Shyong Chwen-Huey, Yehuda Baruch, Wenxia Zhou

\section{- To cite this version:}

Nikos Bozionelos, Giorgos Bozionelos, Konstantinos Kostopoulos, Shyong Chwen-Huey, Yehuda Baruch, et al.. International graduate students' perceptions and interest in international careers. The International Journal of Human Ressource Management, 2015, 26 (11), pp.1428-1451. 10.1080/09585192.2014.935457 . hal-01148009

\section{HAL Id: hal-01148009 \\ https://hal-audencia.archives-ouvertes.fr/hal-01148009}

Submitted on 5 May 2015

HAL is a multi-disciplinary open access archive for the deposit and dissemination of scientific research documents, whether they are published or not. The documents may come from teaching and research institutions in France or abroad, or from public or private research centers.
L'archive ouverte pluridisciplinaire HAL, est destinée au dépôt et à la diffusion de documents scientifiques de niveau recherche, publiés ou non, émanant des établissements d'enseignement et de recherche français ou étrangers, des laboratoires publics ou privés. 


\title{
International Graduate Students' Perceptions and Interest in International Careers
}

Nikos Bozionelos, Giorgos Bozionelos, Konstantinos Kostopoulos, Chwen-Huey Shyong, Yehuda Baruch \& Wenxia Zhou

\begin{abstract}
This research developed and tested a comprehensive model of the antecedents of international graduate students' interest in an international career. Based largely on Social Cognitive Career Theory (SCCT), the model included elements that pertain to perceptions of external constraints (perceptions of the labor market, family pressure to return), international student experience (adjustment in the foreign country during graduate studies, exposure and immersion to the international context), and individual factors (self-efficacy with respect to working abroad and outcome expectancy). Participants were 139 international graduate students in the United Kingdom. Individual factors and perceived constraints were directly related to interest in an international career. The factors that comprised current international student experience were indirectly related to interest via their relationship with self-efficacy, while adjustment moderated the relationship between self-efficacy and interest. Although the hypothesized moderating role of family pressure to return did not materialize, the findings suggest that perceptions of constraints play a more substantial role in the formation of interest
\end{abstract}


than has been assumed by SCCT theory thus far. The findings are discussed with respect to their implications for the literature and for the policies of host country stakeholders.

Keywords: International careers, interest, Social Cognitive Career Theory, international students, graduate students, self-efficacy, adjustment, exposure and immersion, labor market conditions, perceived barriers

International Graduate Students' Perceptions and Interest in International Careers

Globalization leads to a flow of knowledge, information, products, services and people across national borders (e.g., Bartlett, Ghoshal \& Beamish, 2007), and has naturally given substantial rise to international careers. Such careers include moves to and between countries other than an individual's home nation, and are pursued as a means of seizing career and lifestyle opportunities (e.g., Baruch, Dickmann, Altman \& Bournois, 2013; Suutari, Tornikoski \& Makela, 2012). Indeed, the number of people who live and work in countries other than their country of origin is estimated to be in excess of 200 million (e.g., OECD-UNDESA, 2013) and the trend is upwards (Brookfield Global Relocation Services, 2012).

\section{International Graduate Students and International Careers}

\section{The perspective of host countries and firms.}

Globalization has also intensified competition, thus leaving firms with no alternative but to look for the best people irrespective of their country of origin (e.g., Ajami, Cool, Goddard \& Khambata, 2006; Collings, Scullion \& Dowling, 2009). This even extends to companies that only 
operate domestically which, due to a shortage of indigenous labor in developed economies, are in need of non-native talent (Beechler \& Woodward, 2009). Graduate students from abroad (referred to as "international graduate students") are a prime source of such talent (Forster \& Johnsen, 1996) because they possess knowledge, skills and abilities that can be converted into economic benefits for the host countries (Chellaraj, Maskus \& Mattoo, 2008). Indeed, they are the highly skilled foreign workers who account for virtually all of the economic contributions made by international workers to their host countries (Rowthorn, 2008).

Furthermore, international graduate students are typically young and, therefore, do not have family obligations. This means considerable savings in terms of the support packages for spouses and families that host country firms normally provide when they employ skilled professionals from abroad (e.g., Evan, Pucik \& Barsoux, 2002; and see also Peltokorpi \& Froese, 2009). Moreover, international graduate students comprise a substantial population; for example, there were nearly 200,000 international students studying for graduate degrees in the UK in the academic year 2012-13 (UK Council for International Students Affairs, 2014), and in excess of 300,000 international students enrolled in graduate programs in the United States during the same academic year (Institute of International Education, 2013). This means that there is a large pool of highly educated talent for firms in host countries to take advantage of. Indeed, being aware of the benefits that international graduate students can bring, the governments of countries with a tradition in the delivery of graduate studies, such as the UK (Workpermit.com, 2012), 
have developed incentives (e.g., special work visas) to retain the best of them once they graduate (e.g., Geddie, 2013).

\section{The perspective of students themselves.}

From the perspective of international graduate students themselves, they are either starting their careers or have limited work experience and so are soon to enter or return to the labor market. As they live abroad for a relatively long period of time (e.g., up to two years for a Master's course in North America and at least 12 months for a Master's in Europe), they may opt to remain in the host country after their studies are complete to exploit employment opportunities (Baruch, Budhwar \& Khatri, 2007). One reason for this is that they may view work in a developed country as a means of accumulating human capital in the form of experience and prestigious employment that they can "cash in" as enhanced career prospects when returning to their home country (Dustmann \& Weiss, 2007). Indeed, work experience in a developed country may well function as a signal of competence in the home country that may improve employment and career prospects (see Cerdin \& Le Pargneux, 2009). Furthermore, foreign-based study provides an opportunity to dip one's toe into life abroad and explore the international environment, which can trigger thoughts of an international career (see Oosterbeek \& Webbink, 2011).

At this point, it should be noted that international graduate students must be distinguished from international students in general and from international undergraduate students in 
particular. Foreign students who move to developed countries to pursue graduate degrees: are more highly selected, normally pursue more specialized studies, and acquire more advanced skills than their undergraduate counterparts (see, for example, Geddie, 2013; Gungor \& Tansel, 2008; Oosterbeek \& Webbink, 2011). For these reasons, they are of greater value to potential employers in host countries, but are also more attractive to employers back home (see Gungor \& Tunsel, 2008). As a consequence, they normally have more choice when it comes to staying abroad or returning home.

\section{The Present Work}

Despite the rise of international careers, there is very limited research on the factors that shape the interests of the students who are already living abroad to pursue such careers, and much less on graduate students (Geddie, 2013; Mosneaga \& Winther, 2013). As referred to above, this is an important issue for both the students themselves and the host countries. The vast majority of international graduate students who stay abroad upon completion of their studies make their decision after they have moved to the host country (Gungor \& Tansel, 2008; Mosneaga \& Winther, 2013). This means that studying these students when they are pursuing their graduate degrees increases the odds of acquiring a valid idea of the factors that influence that decision and the interplay between them. Such knowledge will assist in the development of advice for host countries and host country education institutions. The present work therefore focuses on international graduate students, who comprise a numerically and substantively important population, with the aim being to develop a comprehensive model of the factors that 
shape their interest in international careers. This model utilizes, among other factors, perceptions of the respondents' experiences during their graduate studies in the foreign country and how these subsequently shape their interest in pursuing an international career.

Empirical work on how the interest of international students in pursuing careers abroad is shaped is very scarce. Baruch et al.'s (2007) study has been the only one thus far to look at antecedents of interest in working abroad among international students. However, though important, this work had a different scope and viewed the issue from the perspective of home countries and the brain drain phenomenon. Nevertheless, its insights were helpful in the development of the model used in the present research. There are also a handful of studies that investigated the receptivity to working abroad of domestic higher education students and early career graduates (e.g., Tharenou, 2003, 2008; Wang \& Bu, 2004). These studies have also provided some important insights. However, their populations of domestic students and recent graduates are substantively different from international students as the latter are already living away from their home countries; meaning that they have taken the step of moving to another culture and have faced some of the challenges of living and performing in a foreign environment. Factors such as foreign language proficiency, for example, which can be an issue for domestic students with respect to their intention to move abroad to work (Wang \& $\mathrm{Bu}, 2004$ ), are much less likely to be an issue for international students. Furthermore, factors that seem to be highly pertinent to shaping the career interests of international graduate students, such as adaptation to the foreign context during their studies abroad, are not relevant to domestic students. 
Nevertheless, these groups also share some similarities, including the possible intention to live and work abroad. As a consequence, these studies were also taken into account in the present work.

\section{Factors influencing students' interest in international careers.}

Direct experience plays an important role in the development of an interest in a particular course of action (Cooke \& Sheeran, 2004; Fazio, Zanna \& Cooper, 1978). International graduate students acquire such experience during their studies. To some extent, international graduate work can be seen as a simulation of working in the foreign environment. This is because students have to deal with cultural and life adaptation issues while simultaneously managing an intensive schedule and having to produce high quality assessed work. That experience is likely to shape their views about whether it would be appropriate for them to pursue professional life in the same way. Although there is a lack of empirical work involving international students per se, studies in other domains indicate that such experiences are important for subsequent interests. For example, the experience of internship appears to influence the intentions of students to pursue careers in the same industry (Lee \& Chao, 2013), or in a location with similar geographic and cultural characteristics, when they graduate (Clark et al., 2013).

Experiential factors, however, must work in concert with other influences in the development of interest towards particular career routes. The way experience, for example, shapes one's direction may be filtered by individual characteristics (Bandura, 1982; Weber, Ruch, Littman-Ovadia, Lavy \& Gai, 2013; Weiss, Freund \& Wiese, 2012). Social Cognitive 
Career Theory (SCCT) (Lent, Brown \& Hackett, 1994, 1996; 2000; Lent et al., 2005) is a theory that has been especially developed to provide a tool for understanding how career interests develop; and suggests an array of factors that interact in the shaping of such interests. SCCT, therefore, can help in the construction of a comprehensive model of antecedents of the desire of international graduate students to pursue an international career.

In particular, SCCT provides a framework for understanding how people develop an interest in particular career moves, which eventually leads to career choices and outcomes. It emphasizes individual (or cognitive-person) factors and perceived external contingencies. Individual factors represent personal agency (Bandura, 1986), namely self-efficacy beliefs and outcome expectations. External contingencies, meanwhile, include perceived constraints (or barriers) and opportunities (Lent et al., 2000). Empirical research suggests that SCCT is a useful general framework for understanding the formation of career interests (e.g., recent meta-analysis by Sheu et al., 2010). In addition, due to its versatility, it can potentially be deployed in various contexts (Ali \& McWhirter, 2006). The work at hand utilized the principles of SCCT in the context of international careers. It developed and tested a model that includes the interplay of perceptions of external (labor markets in the home country and abroad, family pressure to return), experiential (adjustment to the international study experience, exposure and immersion to the international context) and individual (self-efficacy and outcome expectancy) factors in the shaping of international graduate students interest towards the pursuit of international careers.

\section{Hypotheses development}


According to SCCT, external constraints include the conditions of the economy and the labor market, as well as perceived family ties and obligations (Lent et al., 1994; 2000). Lent et al. (2000) assigned a secondary role to such factors because they reasoned that individuals attach low likelihood and low potency to them. The findings of a recent meta-analysis (Choi et al., 2012) provided some support for this view, revealing that a belief in one's ability to make proper career decisions was unrelated to perceptions of career constraints. However, these factors are an integral part of SCCT, and Lent et al. (2000) did note that they are nevertheless real and must be taken into account. In addition, intuitively it would make sense if, for example, perceptions about the condition of the economy back in the home country influence an intention to stay abroad and pursue work there (Al Ariss \& Crowley-Henry, 2013), or if perceived obligations back home play a role in shaping an interest in an international career after the completion of graduate work.

\section{Perceptions of the Labor Market}

SCCT, in line with the push/pull model (Lee, 1966; Ravenstein, 1889), posits that career interests are often influenced by perceptions of labor market conditions and the employment opportunities that they confer (Lent et al. 2000). Concurring with this view, empirical research has shown that a substantial proportion of the individuals who have moved on their own initiative to work abroad (i.e. self-initiated expatriates) made that choice because they perceived that there were limited opportunities in their home country (Froese, 2012; Suutari \& Brewster, 2000). Although international graduate students are already away from their home country, it is likely that they adopt similar reasoning: presuming that staying away from the home country to 
work is a career move, the respective likelihood of finding a job abroad and back home should affect the propensity of these students to pursue work in a foreign country upon completion of their studies. Indeed, if these students perceive that it is relatively easy to obtain employment abroad, but anticipate difficulties in doing so in their home country, they are likely to develop a propensity to stay abroad upon completion of their graduate work and vice versa.

Hypothesis 1: Perceptions of a strong labor market abroad and a weak labor market back home will be positively related to interest in an international career.

\section{Family Pressure to Return}

Concerns about family are a very common reason for hesitation when it comes to considering international career moves (e.g., Brookfield Global Relocation Services, 2011; Selmer \& Lauring, 2011; Tharenou, 2008; Wang \& Bu, 2004). Due to their age, the majority of international graduate students have no spouse or offspring obligations. Nevertheless, they may still be under pressure due to other family ties back home. Such ties can be emotional (e.g., attachment to immediate or extended family members, the disapproval of family in the home country), practical (e.g., caring for elderly parents, helping with the family business) or both. Indeed, Baruch et al. (2007) found that strong ties to family in the home country were negatively associated with the intention of international students to stay and work abroad. A similar conclusion was reached by Soon (2012) with respect to international students in New Zealand. As a consequence, the following hypothesis arises: 
Hypothesis 2: Perceived family pressure to return will be negatively related to interest in an international career.

\section{Current International Student Experience}

SCCT suggests that experiences operate as learning events that shape preferences for certain career courses (Lent et al., 1994). In line with this suggestion, it is reasonable to assume that international graduate students' experiences (positive or negative) and familiarization with the international environment have an impact on their views about pursuing careers abroad.

\section{Adjustment to the international study experience.}

Individuals who have pursued international careers retrospectively report that the desirability of the host country had an effect on their initial decision to work internationally (Doherty, Dickmann \& Mills, 2011). The implication is that anticipation of a positive experience is an influencing factor in the decision to pursue work outside one's home country. This means that the overall experience of studying in the foreign country may affect international graduate students' considerations of whether to work abroad after completing their studies. At the start of their course, international students are newcomers to a different culture and a different education system (Al Hazmi \& Nyland, 2013; Edmonds, 2010; Guo \& Chase, 2011). Accordingly, the nature of the foreign environment during their studies must trigger mechanisms that shape their attitudes towards the host country and the international experience in general. Moreover, they are likely to be more positive towards living and working abroad if they feel comfortable with the place where they are studying and satisfied with their experience. In line with this, Baruch et al. 
(2007) found that the satisfaction of international students with the support of their professors and fellow students was related to their intention to stay in the host country. In the present work, we generalize to the overall graduate study experience abroad and to international careers.

\section{Exposure and immersion to the international context.}

International students are generally on their own when it comes to managing daily life in a foreign country and dealing with any adaptation issues. There is evidence that prior experience of living and working abroad can facilitate adjustment in a subsequent international career move (Bhaskar-Shrinivas, Harrison, Shaffer \& Luk, 2005). Vance’s (2005) qualitative work indicated that activities that expose and familiarize the individual with the international environment (cultural, political, economic, physical), such as travel abroad, working for a foreign firm and involvement in international relations, lay the foundations for a career move abroad. Furthermore, the aforementioned work with students in internships indicates that prior exposure to a location with particular geographic and cultural characteristics increases the likelihood of an individual expressing an intention to work in a similar location upon graduation (Clark et al., 2013). It is therefore reasonable to expect that prior exposure to and immersion in the international context acts as a catalyst for the intention of international graduate students to pursue an international career.

Hypothesis 3: The international students' current experiences, adjustment to the international study experience (H3a) and exposure and immersion to the international context (H3b) will be positively related to interest in an international career. 


\section{Individual Factors}

Finally, SCCT posits that individual factors in the form of personal agency, which includes self-efficacy and outcome expectancy, play a shaping role in career interests. Self-efficacy (Bandura, 1977, 1997) refers to an individual's evaluation of his/her capacity to implement courses of action and persist with them. According to SCCT, self-efficacy exerts a substantial influence over the shaping of interests in specific career-related activities (Lent et al., 1994). Empirical evidence that shows that interest is more likely to develop in cases of strong self-efficacy with respect to a particular career direction and vice versa (Rottinghaus, Larson \& Borgen, 2003), concurs with the predictions of SCCT. As far as international careers are concerned, self-efficacy is conceptualized as the confidence of individuals in their ability to work and live in countries with cultures that are dissimilar to their own (Gianni \& Tharenou, 2000). Working abroad has challenges in both work and non-work domains (e.g., Black, Mendenhall \& Oddou, 1991; Harrison, Shaffer \& Bhaskar-Shrinivas, 2004). Self-efficacy increases the probability of setting challenging goals (e.g., Waung, Macneil \& Vance, 1995). Accordingly, international graduate students with greater self-efficacy must be more likely to believe that they are able to cope with those challenges, suggesting that they must report a greater propensity to pursue an international career.

Outcome expectancy is defined as the perceived result of following certain courses of action (Vroom, 1964). SCCT proposes that people develop an interest in particular career moves when they expect overall positive outcomes (Lent et al., 1994), and this is a proposition that is 
supported by empirical evidence (Sheu et al., 2010). Accordingly, when international graduate students consider whether to stay abroad, they should assess the potentially positive and negative outcomes of doing so and then estimate the net value of the result. A positive net value, or valence, of the overall outcome would increase interest in working abroad and vice versa. Although this appears to be logically sound, studies with domestic students have produced mixed results. Wang and $\mathrm{Bu}$ (2004) failed to find in Canadian undergraduates a consistent relationship between perceived advantages of international over domestic careers and an interest in pursuing international assignments. On the other hand, Tharenou (2003) found that domestically employed graduates reported greater receptivity to international assignments if they had positive expectations about outcomes. Nonetheless, the logic of expectancy theory and some of the extant findings with domestic students and recent graduates justify the following hypothesis:

Hypothesis 4: Individual factors, self-efficacy in working abroad (H4a) and outcome expectancy (H4b) will be positively related to the interest of international graduate students in an international career.

Furthermore, there is reason to speculate that the influence of perceived constraints and current international student experience is materialized via the individual factors of self-efficacy and outcome expectancy. Indeed, self-efficacy is cultivated by exposure to the target object and experiences of success with respect to it (Bandura, 1997, 2002; Grunert \& Bodner, 2011; Scholz, Sniehotta, Schuz \& Oeberst, 2007). Given that adjustment to the foreign context is an indication of success, it follows that the international graduate students who perceive that they have adapted 
well to the foreign environment and those who have gained exposure to the international context should report greater self-efficacy with respect to working abroad. Given that self-efficacy has been hypothesized to relate to interest in an international career, a mediation expectation ensues. The expectation is for partial mediation for exposure and immersion, because that factor refers to the accumulation of experiences that are not temporally restricted to the period of graduate study, but extend before the individual has moved to the foreign country to pursue graduate work.

Hypothesis 5: Self-efficacy in working abroad will fully and partially mediate, respectively, the relationship of both adjustment to the international study experience $(\mathrm{H} 5 \mathrm{a})$ and exposure and immersion to the international context $(H 5 b)$ with an interest in an international career.

Furthermore, the students who perceive a buoyant labor market abroad and a tight market back home should anticipate better outcomes from pursuing a career abroad. This means that perceptions of the labor market should relate to expectations of benefits from working in a foreign country. The latter has in turn been hypothesized to relate to interest in an international career, which directs us towards a mediating role for outcome expectancy in the relationship between labor market perceptions and interest. Moreover, those who perceive greater opportunities abroad compared to their home country may unconsciously develop inflated views of their capacity to successfully face the challenges of living and working abroad. This would then function as a self-enhancement motivation mechanism (e.g., Alicke \& Sedikidis, 2009; Willard \& Gramzow, 2009) with respect to their preference to stay and work abroad instead of 
going back home. This directs us towards a mediating role for self-efficacy in the relationship between labor market perceptions and interest in an international career.

Hypothesis 6. Outcome expectancy $(H 6 a)$ and self-efficacy in working abroad $(H 6 b)$ will partially mediate the relationship of perceptions of labor markets with interest in an international career.

Finally, Lent et al. (2000) within the framework of SCCT suggest that apart from having a predictor role, perceived constraints may also play a moderator role in the process of forming career preferences. Indeed, it is legitimate to expect that among those students who believe in their ability to face the difficulties of living and working abroad, those who perceive more intense family pressure to return will report less interest in an international career than those who perceive less of this pressure. In other words, the highest level of interest will be expressed by those who simultaneously possess strong self-efficacy and perceive weak family pressure. Similarly, among those who hold strong outcome expectations, those who perceive strong family pressure to return should be more restrained in their interest in pursuing a career abroad than their counterparts who perceive weaker family constraints.

Hypothesis 7. Family pressure to return will moderate the relationship between individual factors and interest in an international career. In particular, the relationship of both self-efficacy in working abroad $(H 7 a)$ and outcome expectancy $(H 7 b)$ with interest will be stronger when family pressure is weak. 
SCCT theory itself and empirical studies that employ it limit their speculation with respect to moderating effects to perceived constraints only (e.g. Lent et al., 1994, 1996, 2000, 2005). The context of the present work, however, justifies the belief that other factors may also assume moderator roles. In particular, it appears reasonable to consider that feeling comfortable and at ease with the foreign environment during graduate work magnifies the effects of self-efficacy on interest; those who are better adjusted to the lifestyle and study conditions of the host country and also have a strong belief in their capacity to live and work abroad must be particularly likely to develop a propensity to pursue an international career.

Hypothesis 8. Adjustment to the international study experience will moderate the relationship between self-efficacy in working abroad and interest in an international career. The relationship will be strongest when there are high levels of adjustment.

The hypotheses are depicted in Figure 1, including direct, indirect and moderator effects.

\section{Method}

\section{Participants and Procedure}

Participants were 139 (45 males and 94 females) international students undertaking Master's courses at a British university (Master's courses in the United Kingdom last for one year). All of the participants were in the final stages of their studies (i.e. the dissertation stage that occupies the last three months of the 12-month course). These individuals were ideal for the research because they had accumulated experiences from studying and living in the host country and were near to completing their academic work. This means that decisions about whether to 
stay abroad or return home were imminent. Participation was solicited via the sending of emails

to lists of students who were enrolled in graduate courses. Questionnaires were administered electronically using internet-based specialist software and remained open for 15 days.

The demographics of the sample are presented in Table 1. Participants came from 21 different countries and four continents: Asia (including the Far East, South-East Asia and the Middle East), North America, Europe and Oceania. Two thirds of the participants were enrolled in courses on business-related subjects.

\section{Measures}

The response format was a 7-point metric (1: strongly disagree to 7: strongly agree) unless otherwise stated. The questionnaire language was English, because all of the participants were graduate students in the United Kingdom with English as the language of instruction.

Interest in an international career. This was measured with five items adapted from Adler's (1986) scale of interest in working abroad. The participants were provided with the following definition of an international career: "relocating abroad to work as a full-time employee in a foreign country for a substantial period of time." Sample items included: "I am seriously considering pursuing an international career" and "I want my first job after graduation to be in a foreign country." Cronbach $\alpha$ was .82 .

Labor market perceptions. The participants' perceptions of the condition of the labor market in and outside their home country were assessed with two and three items, respectively. These items were adapted from Baruch et al. (2007) to suit international graduate students who might 
consider employment outside their home country. The items were positively and negatively stated, with the latter reversed in the scoring process. Sample items include: "I have a good chance of getting a good job in my home country" and "there are many good jobs outside my home country for those who want to get ahead." Cronbach alphas for perceptions of the home and foreign labor markets were .69 and .86 , respectively.

Family pressure to return. This was measured with four items adapted from Tharenou (2003). Sample items included: "I prefer to go back and live with my family when I graduate" and "my family's approval would be important to my taking of a job abroad." Cronbach $\alpha$ was .82 .

Adjustment to the international study experience. This was assessed with three items adapted from Baruch et al. (2007). A sample item is: "the adjustment process to a different culture from my own during my studies was smooth." Cronbach $\alpha$ was .70.

Exposure and immersion to the international context. This was assessed with six items that were developed from Vance's (2005) list of foundation activities that may lay the ground for pursuing careers abroad. Sample items include: "I have traveled abroad a lot" and "I participated in international relations activities (e.g., clubs, associations) before the start of my postgraduate studies." Cronbach alpha was .63. Concerns over the marginal Cronbach alpha were allayed by the results of both a Confirmatory Factor Analysis (CFA) and the testing for common method bias. 
Self-efficacy in working abroad. This was assessed with Gianni and Tharenou's (2000) 12-item scale. The scale adopts an 11-point measurement format (from $0 \%$ to $100 \%$, with $10 \%$ increments in-between), with each point reflecting a different level of confidence in one's capacity to work and live in a foreign country. Sample items include: "work with co-workers who have different values from my own" and "adapt my behavior to fit into the culture of the country in which I accept a job.” Cronbach $\alpha$ was .91.

To examine the factor structure and discriminant validity of the above measures, a CFA was performed on the final sample of 139 participants with the EQS 6.1 Structural Equations Program (Bentler, 2004), employing the maximum likelihood robust method that corrects for non-normality in data. The seven-factor model demonstrated good fit (Satorra-Bentler scaled $\chi^{2}$ $[217, N=139]=382.5, p<.001 ; \mathrm{CFI}=.951 ; \mathrm{IFI}=.950 ; \mathrm{RMSEA}=.064)$, and an improvement over the independence model $\left(\Delta \chi^{2}=1175.9, p<.001\right)$. All of the factor loadings exceeded .45 and were significant at the .001 level.

Outcome expectancy. In line with expectancy theory, this was operationalized as the product of perceptions of instrumentality and valence (Vroom, 1964). Using an 11-point response format (range from $0 \%$ to $100 \%$, with $10 \%$ increments in-between), instrumentality was assessed as the perceived likelihood of outcomes that might occur in the case of taking a job abroad. Valence, meanwhile, was assessed as the desirability of each of these outcomes, also using an 11-point response format (range from 0\%: not at all desirable, to 100\%: extremely desirable, with 10\% increments in-between). Outcomes (13 overall) were developed by consulting earlier work that 
was relevant to the present study (e.g., Tharenou, 2003, 2008; Wang \& Bu, 2004) and covered the four domains proposed by Tharenou (2003): personal development and cross-cultural experiences, social factors, career advancement, and daily living. Sample items include: "add to my knowledge of the world and of other cultures", "put some of my personal relationships at risk", "progress in my career at a faster rate" and "need more time to establish a social network." Negatively stated items were reversed in the scoring process. What was assessed with this measure was the participants' subjective sense of the probability of a valued outcome in the case of staying in a foreign country to work. Cronbach $\alpha$ was .86 and .81 for instrumentality and valence, respectively.

The discriminant and convergent validity of the instrumentality and valence scales was supported by a CFA, where the two-factor model showed good fit (Satorra-Bentler scaled $\chi^{2}[26$, $N=139]=54.4, p<.001 ; \mathrm{CFI}=.962 ; \mathrm{IFI}=.959 ; \mathrm{RMSEA}=.061)$ and was an improvement over the independence model $\left(\Delta \chi^{2}=386.6, p<.001\right)$. The factor loadings were above .55 and significant at the .001 level.

To further test for the presence of common method variance, a Harman single-factor test was first conducted on all of the study's items (e.g., Podsakoff, MacKenzie, Lee \& Podsakoff, 2003). The test produced negative results, as no single factor explained more than $20 \%$ of the total variance. However, following the recommendations of Chang, Van Witteloostuijn and Eden (2010), and the related procedures described in Podsakoff et al. (2003), we went a step further. This involved constructing one unmeasured common method variance (CMV) factor that was 
linked to the indicators of the constructs included in the above CFA models. The CMV factor did not change the outcomes of the CFAs. Taken together, the results of these tests lead to increased confidence that common method variance was not present in the data.

Pertinent, but distinct from common method bias, is the issue of self-generated validity, which refers to the possibility that the form and structure of the questionnaire (e.g., order of measures) induces participants to respond in ways that are in line with the relationships and causal ordering that the researchers have in mind (e.g., Chandon, Morwitz \& Reinartz, 2005; Feldman \& Lynch, 1988). To reduce the likelihood of self-generated response bias, a number of measures were adopted, including: reassuring respondents about anonymity, stressing in the instructions that "there are no right or wrong answers", including the demographic questions at the start of the questionnaire, and placing the scales in a different order from the one we had in mind for the model (for example, the scale of interest was placed in the middle of the questionnaire). In addition, the questionnaire was piloted with 10 (five female and five male) international graduate students, who were asked to complete the scales and verbally transfer their comments to the researchers. The pilot testing revealed that the students utilized the full range of the response scale in all measures. In addition, it suggested that the instructions were clear, the items were intelligible and had unambiguous meanings, and the electronic version of the questionnaire was functioning smoothly.

Controls. Demographics were measured with single items and included: gender (1: male; 2: female); age; region of origin (countries were categorized as follows: Far East \& South East 
Asia; Middle East and South Asia; and Western: European countries, North America, Australia and New Zealand) that was represented in the analysis with two dummies; Master's major (coded 1: business related; 2: non-business related); length of total work experience (in months); and length of work experience outside the home country (in months). Empirical research suggests differences between genders, age cohorts (e.g., Tharenou, 2003), and geographic region of origin (Baruch et al., 2007) in terms of receptivity to pursuing careers outside the home country. In addition, economic conditions vary across geographic regions, which may act as a "push" factor influencing many parts of the model, including outcome expectancy and labor market perceptions. Furthermore, SCCT suggests that educational background influences the shaping of career interests (Lent et al, 2000), while empirical evidence indicates that business students are better at building self-efficacy than students from other disciplines (Chung, Schwager \& Turner, 2002). Finally, Vance's (2005) work suggested that temporary international work experience (e.g., an internship in another country) may contribute to subsequent decisions about international career moves.

\section{Results}

Descriptive statistics and inter-correlations are presented in Table 1. Generally, the participants as a group had a substantial interest in international careers $(M=5.17, S D=1.14)$, and also held rather strong self-efficacy beliefs regarding living and working abroad $(M=$ $71.39 \%, S D=12.90 \%$ ). On the other hand, perceptions of family pressure to return were also of considerable strength $(M=4.69, S D=1.47)$. 


\section{Hypotheses testing.}

The hypotheses were tested with a path analysis (i.e. manifest variables) using the EQS 6.1

Structural Equations Program. The path analysis approach was chosen because it preserves power, but also permits the simultaneous estimation of multiple causal relationships and the testing of moderation and mediation effects (Kline, 2005). To have confidence in the reliability of the path estimates, authors recommend a minimum sample size of 100 (Bollen, 1989; Hair, Anderson, Tatham \& Black, 1998). Accordingly, our sample of 139 cases clearly exceeded this benchmark. In addition, because we employed path analysis with manifest variables (i.e. averaging multi-items constructs), the sample size also exceeded the recommended ratio of five observations per model parameter to-be-estimated (Bentler \& Chou, 1988; Kline, 2005).

Having established the measurement properties and discriminant validity of the measures, mean computations were utilized to create the manifest variables. Estimations (maximum likelihood robust method) took into account the controls, and so the final model was held over and above the effects of the controls. In the calculation of interaction terms (e.g., family pressure to return $\mathrm{x}$ self-efficacy), the variables were mean-centered to reduce multicollinearity and produce less biased parameter estimates. Although mean-centering may not always rule out multicollinearity (Echambadi \& Hess, 2007), it has long been considered (Cohen, Cohen, West \& Aiken, 2003; Aiken \& West, 1991) and widely utilized (e.g., Bode, Wagner, Petersen \& Ellram, 2011; Faraj \& Yan, 2009) as one of the best available ways to alleviate pertinent concerns. In addition, we tested for multicollinearity by inspecting the variance inflation factor 
(VIF) indices. Their mean values were well below the conservative threshold of five (Cohen et al., 2003), suggesting that multicollinearity was not a significant concern. To test the mediator hypotheses (i.e., Hypotheses 5 and 6), direct and indirect effects were requested following related procedures in EQS that generate standard errors and path coefficients for these effects (Bentler, 2004).

The model with the path estimates (beta coefficients) that test hypotheses is presented in Figure 2. The path from self-efficacy towards outcome expectancy was not part of the hypotheses. Nevertheless, it represents a theoretically (Bandura, 1986; Lent et al., 2004) and empirically established path (Sheu et al., 2010) that also depicts the indirect effect of self-efficacy on interest. The model demonstrated very good data fit with a non-significant Satorra-Bentler scaled $\chi^{2}(87, \mathrm{~N}=139)=95.5(n s)$ and a very satisfactory performance in the other fit statistics $(\mathrm{CFI}=.976 ; \mathrm{IFI}=.980 ; \mathrm{RMSEA}=.027)$.

The total effect of perceptions of labor markets on interest in an international career was significant $(\beta=.17, p<.05)$, and Hypothesis 1 was thus supported. Family pressure to return was negatively related to interest $(\beta=-.15, p<.05)$, which lent support to Hypothesis 2 . The total, direct and indirect effects on interest of adjustment to the international study experience ( $\beta$ $=.12, p<.05)$ and exposure and immersion to the international context $(\beta=.23, p<.01)$ were also significant, lending support to Hypotheses $\mathrm{H} 3 \mathrm{a}$ and $\mathrm{H} 3 \mathrm{~b}$, respectively, and therefore full support to Hypothesis 3. 
Self-efficacy in working abroad $(\beta=.20, p<.05)$ and outcome expectancy $(\beta=.26, p<.01)$ were positively related to interest in an international career, meaning that both parts of Hypothesis 4 were supported. However, the total effects were significant because of the significance of the indirect effects. The direct effects of these variables on interest were not significant $(\beta=-.04, n s$, and $\beta=.10, n s$, respectively). This suggested only partial support for Hypothesis 5, because self-efficacy fully mediated the relationship between both adjustment (H5a) and exposure and immersion (H5b) and interest, rather than just the former. On the other hand, Hypothesis 6 received no support. Perceptions of labor markets were related with neither outcome expectancy $(\beta=.06, n s)$ nor self-efficacy $(\beta=-.10, n s)$, suggesting that these variables could not mediate the relationship of labor market perceptions with interest in an international career. Perceptions of labor markets were only directly related to interest $(\beta=.18, p<.05)$.

With respect to the moderation hypotheses, perceived family pressure to return failed to moderate the relationship of self-efficacy and outcome expectancy with interest $(\beta=.06, n s$, and $-.07, n s$, respectively), meaning that both parts of Hypothesis 7 were unsupported. On the other hand, adjustment to the international study experience had a significant moderating effect on the relationship between self-efficacy and interest $(\beta=.15, p<.05)$. This result was interpreted using the procedure suggested by Aiken \& West (1991), and the plot is shown in Figure 3. The strongest interest was expressed by those who reported high adjustment and strong self-efficacy, lending support to Hypothesis 8 . It should be noted that the lowest interest was reported by those with high adjustment and low self-efficacy. 
For reasons of elegance and clarity, a final model was prepared to include only significant paths. The model, which is presented in Figure 4, demonstrated an excellent data fit [Satorra-Bentler scaled $\left.\chi^{2}(58, N=139)=61.6, n s ; \mathrm{CFI}=.990 ; \mathrm{IFI}=.992 ; \mathrm{RMSEA}=.021\right]$. The retained path coefficients revealed an identical pattern to the original path model (Figure 2).

Finally, a number of alternative models, which covered virtually all potential variable orderings, were tested. Among them were a model with the entirely reverse causality order of our proposed model (i.e. interest in self-expatriation as the exogenous variable on the left-hand side), and a model with the individual factors (self-efficacy and outcome expectancy) as exogenous variables. All of these models (seven in number) had poor data-fitting properties (range of Satorra-Bentler scaled $\chi^{2}=85.6-144.3$, all $p<.001 ;$ range of CFI $=707-864 ;$ range of IFI $=743$ -872 ; range of RMSEA = .13 - .09).

\section{Discussion}

The aim of the research was to develop a comprehensive model of factors, along with their interplay, that shape the interest of international graduate students in pursuing international careers. These students are a significant population, whose decisions as to whether they will return home or pursue a career abroad after completion of their studies is of substantive interest to all of the parties involved, and especially to host country firms, governments and education institutions. The model included experiential, individual and perceived constraint factors, and was generally vindicated by the results. The findings attested to the important role of experiential factors, such as the experience acquired during graduate work in the host country. In addition, 
the study lends further support to the validity of SCCT by providing evidence on its applicability in the context of decisions made concerning an international career by individuals who are pursuing graduate studies abroad. There is, however, one caveat: the findings suggest a role for family pressure in the shaping of interest, which is somewhat at odds with the secondary role assigned to perceived constraints by the proponents of SCCT (Lent et al., 2000). Furthermore, the findings vindicate the push/pull idea, because the combination of perceptions of strong employment opportunities abroad with weak opportunities back home was directly related to an enhanced interest in staying and working abroad. Finally, the model indicated a dynamic relationship between the factors.

The degree to which international graduate students felt adjusted during their studies contributed to the shaping of their tendency to pursue international careers. Adjustment during the experience as a graduate student reflects the extent to which the foreign country is viewed as welcoming and as offering high quality education services. As noted, in the global war for talent, governments of countries that are popular education destinations have implemented schemes to entice high caliber foreign graduate students to stay and work there. As a consequence, relevant retention schemes will have a higher probability of success if a concerted effort is made in a variety of domains, including the quality of experience that higher education establishments offer to students from abroad and the way those students are integrated into the foreign university community. Surprisingly, higher education institutions in countries that are traditional providers of graduate education have apparently not paid enough attention to the issue (e.g., Henning, 
Krageloh, Moir, Doherty \& Hawken, 2012; Kim, 2011; Sherry, Thomas \& Chui, 2010), even though integration programs for international students are available and pilot research indicates that they pay dividends when properly implemented (Guo \& Chase, 2011). However, education establishments do not exist in a vacuum; governments and host country firms should work in tandem with those providing an education to international graduate students so that they are able to deliver the experience that these students expect (for example, quality internships). Such an approach should also seek to smooth the adaptation process and provide a pleasant environment during graduate work. Indeed, some suggest that the process of integration should start before students leave their home country, and must include preparation programs delivered by the host nation and its institutions (Cetinkava-Yildiz, Cakir \& Kondakci, 2011).

The importance of adjustment was further highlighted by the results of the moderation testing, not only because they suggested that adjustment magnifies the relationship between self-efficacy and interest, but particularly because they indicated that a lack of adjustment renders self-efficacy ineffective in creating interest in an international career. This pattern grants a key role to adjustment, which means that special attention should be paid to it by host country firms and governments in their endeavors to retain international graduate students, and perhaps international students in general, upon their graduation.

Previous exposure and immersion to the international environment was also associated with a propensity towards undertaking an international career. In fact, its effect was stronger than that of adjustment during graduate work. Exposure and immersion reflect experiences that mainly 
occur before the graduate study experience in the host country. Such experiences have more time to consolidate in the memory, and this may be the reason why they contribute more to an interest in staying and working abroad.

Those international graduate students who held stronger self-efficacy beliefs in terms of dealing with the challenges of living and working in a foreign country, and expected better overall outcomes from staying abroad to work, were more positive towards an international career. The importance of self-efficacy and outcome expectancy was reiterated by two more findings. The first of these was the failure of perceived family pressure to moderate the relationship with interest. This means that those who held strong self-efficacy beliefs and expectations of substantial benefits from working abroad were not deterred by links and obligations back home. Second, the effects of adjustment and exposure and immersion were exerted exclusively via self-efficacy in working abroad. Self-efficacy and outcome expectancy have a central role in SCCT, and also appear to play a part in the propensity of domestic students to make career moves abroad (see Tharenou, 2008). The present work suggested a central role for these factors, and especially for self-efficacy, in the development of a propensity towards having an international career by those who have already made the transition abroad to obtain advanced degrees. Self-efficacy is the cornerstone of personal agency (Bandura, 2001), and the logical explanation for its emergence as a pivotal factor in the present work is because living and working in a foreign country is normally a challenging endeavor. 
With respect to host country efforts in seeking to retain quality foreign graduate students, the substantial effect of outcome expectancy implies that host nations should carefully manage the outcome expectations of potential international careerists. If anticipated valued outcomes are not realized, retaining these talented foreigners and keeping them motivated may be difficult, while other potentially worse outcomes, such as cynicism towards the host country and its institutions, may also develop. In fact, some preliminary findings suggest that such expectations may not be properly managed, as foreigners employed in highly skilled occupations in developed countries tend to report lower job satisfaction than their native counterparts (Sabharwal, 2011). Therefore, notwithstanding their desire to retain international graduate students, host country governmental agencies and firms should take care to not create unrealistic expectations. Research in the expatriation domain suggests that forming realistic pre-departure expectations about the difficulty to adapt increases the likelihood that these are met or exceeded during the assignment, which in turn favors adaptation, and vice versa (e.g., see Caligiuri, Phillips, Lazarova, Tarique \& Burgi, 2000). Although extrapolation to international graduate students may not be absolutely safe, the importance of creating realistic expectations and trying to meet these is clear.

Finally, the negative effect of family pressure on interest should be viewed in conjunction with the corresponding descriptive statistic, which indicated that the participants attached considerable importance to that factor. This contrasts the tentative conclusion of Lent et al. (2000) that individuals generally overlook constraints. These authors developed their theory as a general theory of career interest and choice. However, the present findings do suggest that the 
theory may need to be adapted according to contextual and population features. International graduate students find themselves in substantial geographical distance from their families and have already experienced the effects of that separation during their studies. Staying abroad will extend the separation with all its inherent consequences, both emotional and practical. It appears, therefore, to be natural that family constraints operate as a deterrent to international career considerations. This may not be the case in decisions about domestic moves (e.g., moving to another location within the same country). It may likewise not be the case with the kinds of decision that SCCT has mostly focused on so far, such as choice of education major or occupation. This highlights the potential importance of context, and is another contribution of the present work.

\section{Limitations and Future Directions}

The model in this research was developed with theory and logic in mind, and demonstrated very satisfactory data-fitting properties. In addition, no alternative causal model showed acceptable data-fitting properties. However, the fact remains that the data were collected at a single point in time, and only studies with multiple measurement points are able to remove all doubt about causal order. As an illustration, there is some likelihood that exposure and immersion and interest in an international career simply co-vary but they are not causally linked. Both of them may represent manifestations of a general interest or preference for internationally oriented experiences. Appropriately designed longitudinal studies should allow us to look at such issues. 
The use of self-reports raises the possibility of common method bias and self-generated validity. Nevertheless, precautions were taken to protect from these phenomena. Furthermore, the extensive testing conducted was overwhelmingly negative with respect to the presence of common method effects. It should also be noted that the factors in the model represented individuals' own perceptions and beliefs, and self-reports arguably represent the most appropriate method to tap these (see Spector, 1994; 2006).

What the model predicts is in essence the intentions of international graduate students to pursue career moves outside their home country. Intentions are not actual behaviors, but they are good predictors of them (Krauss, 1995; Sutton, 1998), especially when formed by direct experience, as in the present work (Glasman \& Albarracin, 2006). Nonetheless, various elements and events may intervene to prevent intentions from being translated into actual behavioral outcomes (Ajzen \& Fishbein, 2005). Accordingly, factors that are beyond the control of graduate students may impede the conversion of interest into actually pursuing a career abroad. These may include, for example, whether students will be able to obtain work permits and whether they will be able to find a position that meets their career aspirations. As a consequence, future research should extend the model to include factual outcomes.

Dispositional factors, which are not part of SCCT, may further help us to understand tendencies towards having an international career. Such factors include personality traits. For example, extraversion and emotional stability relate to the development of self-efficacy (Gerhardt \& Brown, 2006). This means that these traits may impact the interest of international 
graduate students in living and working abroad via their effects on self-efficacy. In fact, expatriates who score higher on extraversion and emotional stability are less likely to express an intention to prematurely terminate their assignments (Caligiuri, 2000). Although international students are different from expatriates, and interest in an international career is also different from a desire to abort an international assignment, this implies that the above contemplation may hold true. Future research could therefore also take into account the impact of personality.

The present work revealed a role for constraints, in the form of perceived family pressure to return, in a deviation from the views expressed within SCCT. Future research should delve more deeply into contextual and population characteristics as determinants of the role of barriers in the shaping of interest in international careers. Whether perceptions of constraints acquire weight only under certain circumstances or for particular populations (for example, most of the participants in the present study came from collectivistic cultures where family ties play a central role) is an important issue that needs to be clarified by future research.

Finally, international careers take various forms that we are gradually coming to understand (Baruchet al., 2013; Shaffer, Kraimer, Chen \& Bolino, 2012). These forms differ substantially (e.g., short vs. long term, amount of travel involved, where the individual is based). Accordingly, the weighting of factors and their interplay may differ according to the content of the international career. For example, there is some evidence that people judge international assignments differently according to whether they are short or long-term (Konopaske, Robie \& Ivancevich, 2005). This could mean that an international career comprised of multiple short-term 
assignments may be viewed differently than a career that requires long-term relocation in a distant culture. Future research could therefore adopt a more fine-grained approach and seek to adapt the model to fit particular types of international careers. Similarly, adjustment to the foreign culture and ways of living is apparently multi-dimensional (Haslberger, Brewster \& Hippler, 2013). The same may hold in the case of international graduate students' adjustment to their studies abroad. Its dimensions may affect interest towards international careers through variant routes (e.g., by impacting different intervening factors), and this is something that future research can also investigate.

\section{References}

Adler, N. J. (1986). Do MBAs want international careers? International Journal of Intercultural Relations, 10, 277-300.

Aiken L., \& West, S. (1991). Multiple regression: Testing and interpreting interactions. Newbury Park, CA: Sage.

Ajami, R. A., Cool, K., Goddard, G. J., \& Khambata, D. (2006). International business: Theory and practice (2nd ed.). Armonk, USA: M. E. Sharpe.

Ajzen, I., \& Fishbein, M. (2005). The influence of attitudes on behavior. In D. Albarracín, B. T. Johnson, \& M. P. Zanna (Eds.), The handbook of attitudes (pp. 173-221). Mahwah, NJ: Erlbaum. 
Al Ariss, A., \& Crowley-Henry, M. (2013). Self-initiated expatriation and migration in the management literature: Present theorizations and future research directions. Career Development International, 18, 78 - 96.

Al Hazmi, A., \& Nyland, B. (2013). The Saudi Arabian international student experience: From a gender-segregated society to studying in a mixed-gender environment. Compare: A Journal of Comparative and International Education, 43, 346-365.

Ali, S. R., \& McWhirter, E. H. (2006). Rural Appalachian youth's vocational/educational postsecondary aspirations: Applying social cognitive career theory. Journal of Career Development, 33, 87-111.

Alicke, M. D., \& Sedikidis, C. (2009). Self-enhancement and self-protection: What they are and what they do. European Review of Social Psychology, 20, 1-48.

Bandura, A. (1977). Self-efficacy: Toward a unifying theory of behavioral change. Psychological Review, 84, 191-215.

Bandura, A. (1982). The psychology of chance encounters and life paths. American Psychologist, $37,747-755$.

Bandura, A. (1986). Social foundations of thought and action: A social cognitive theory. Englewood Cliffs, NJ: Prentice-Hall.

Bandura, A. (1997). Self-efficacy: The exercise of control. New York: Freeman.

Bandura, A. (2001). Social cognitive theory: An agentic perspective. Annual Review of Psychology, 52, 1-26. 
Bandura, A. (2002). Social foundations of thought and action. In D. F. Marks (Ed.), The health psychology reader (pp. 94-106). London: Sage.

Bartlett, C. A., Ghoshal, S., \& Beamish P (2007). Transnational management: Text, cases, and readings in cross-border management (5th ed.). London: McGraw-Hill.

Baruch, Y., Budhwar, P. S., \& Khatri, N. (2007). Brain drain: Inclination to stay abroad after studies. Journal of World Business, 42, 99-112.

Baruch, Y., Dickmann, M., Altman, Y., \& Bournois, F. (2013). Exploring international work: Types and dimensions of global careers. International Journal of Human Resource Management, 24, 2369-2393.

Beechler, S., \& Woodward, I. C. (2009). The global "war for talent". Journal of International Management, 15, 273-285.

Bentler, P. M. (2004). EQS 6 structural equations program manual. Encino, CA: Multivariate Software, Inc.

Bentler P. M., \& Chou C. P. (1988). Practical issues in structural modeling. J. S. Long (Ed.), Common problems/proper solutions: Avoiding error in quantitative research (pp. 161-192). Newbury Park, CA: Sage.

Bhaskar-Shrinivas, P., Harrison, D.A., Shaffer, M. A., \& Luk, D. M. (2005). Input-based and time-based models of international adjustment: Meta-analytic evidence and theoretical extensions. Academy of Management Journal, 48, 257-281. 
Black, J. S., Mendenhall, M., \& Oddou, G. (1991). Towards a comprehensive model of international adjustment: An integration of multiple theoretical perspectives. Academy of Management Review, 16, 291-317.

Bode, C., Wagner, S. M., Petersen, K. J., \& Ellram, L. M. (2011). Understanding responses to supply chain disruptions: Insights from information processing and resource dependence perspectives. Academy of Management Journal, 54, 833-856.

Bollen K. A. (1989). Structural equations with latent variables. New York: Wiley.

Brookfield Global Relocation Services (2012). Global relocation trends: 2012 survey report. Chicago, IL: Brookfield Global Relocation Services.

Caligiuri, P. (2000). The big-five personality characteristics as predictors of expatriate's desire to terminate the assignment and supervisor-rated performance. Personnel Psychology, 53, $67-78$.

Caligiuri, P., Phillips, J., Lazarova, M., Tarique, I., \& Burgi, P. (2001). The theory of met expectations applied to expatriate adjustment: The role of cross-cultural training. International Journal of Human Resource Management, 12, 357-372.

Cerdin, J-L., \& Le Pargneux, M. (2009). Career and international assignment fit: Toward an integrative model of success. Human Resource Management, 48, 5-25.

Cetinkava-Yildiz, E., Cakir, S. G., \& Kondakci, Y. (2011). Psychological distress among international students in Turkey. International Journal of Intercultural Relations, 35, 534-539. 
Chen, C-T, \& Chen, C-F. (2011). The influence of internship experiences on the behavioral intentions of college students in Taiwan. Asia-Pacific Education Researcher, 20, 73-92.

Chellaraj, G., Maskus, K. E., \& Mattoo, K. (2008). The contribution of international graduate students to US innovation. Review of International Economics, 16, 444-462.

Chandon, P., Morwitz, V. G., \& Reinartz, W. J. (2005). Do intentions really predict behavior? Self-generated validity effects in survey research. Journal of Marketing, 69, 1-14.

Chang, S-J., Van Witteloostuijn, A., \& Eden, L. (2010). From the editors: Common method variance in international business research. Journal of International Business Studies, 41, 178-184.

Choi, B. Y., Park, H., Yang, E., Lee, S. K., Lee, Y., \& Lee, S. M. (2012). Understanding career decision self-efficacy: A meta-analytic approach. Journal of Career Development, 39, 443-460.

Chung, S. H., Schwager, P. H., \& Turner, D. E. (2002). An empirical study of students' self-efficacy: Differences among four academic disciplines at a large university. Journal of Computer Information Systems, 42(4), 1-6.

Clark, T. R., Freedman, S. B., Croft, A. J., Dalton, H. E., Luscombe, G. M., Brown, A. M.... Frommer, M. S. (2013). Medical graduates becoming rural doctors: Rural background versus extended rural placement. Medical Journal of Australia, 11, 779-782.

Cohen, J., Cohen, P., West, S. G., \& Aiken, L. S. (2003). Applied multiple regression/correlation analysis for the behavioral sciences (3rd ed.). Mahwah, NJ: Lawrence Erlbaum. 
Collings, D. G., Scullion, H., \& Dowling, P. J. (2007). Global staffing: A review and thematic research agenda. The International Journal of Human Resource Management, 20, 1253-1272.

Cooke, R., \& Sheeran, P. (2004). Moderation of cognition-intention and cognition-behaviour relations: A meta-analysis of properties of variables from the theory of planned behaviour. British Journal of Social Psychology, 43, 159-186.

Doherty, N., Dickmann, M., \& Mills, T. (2011). Exploring the motives of company-backed and self-initiated expatriates. International Journal of Human Resource Management, 22, 595-611.

Dustmann, C., \& Weiss, Y. (2007). Return migration: Theory and empirical evidence from the UK. British Journal of Industrial Relations, 45, 236-256.

Echambadi, R., \& Hess, J. D. (2007). Mean-centering does not alleviate collinearity problems in moderated multiple regression models. Marketing Science, 26, 438-445.

Edmonds, M. L. (2010). The lived experience of nursing students who study abroad: A qualitative inquiry. Journal of Studies in International Education, 14, 545-568.

Evan, P., Pucik, V., \& Barsoux, J. L. (2002). The Global challenge: Frameworks for international human resource management. New York: McGraw-Hill.

Faraj, S., \& Yan, A. (2009). Boundary work in knowledge teams. Journal of Applied Psychology, 94, 604-617. 
Fazio, R. H., Zanna, M. P., \& Cooper, J. (1978). Direct experience and attitude-behavior consistency: An information processing analysis. Personality \& Social Psychology Bulletin, $4,48-51$.

Feldman, J. M., \& Lynch, J. G. Jr. (1988). Self-generated validity and other effects on measurement on belief, attitude intention, and behavior. Journal of Applied Psychology, 73, 421-435.

Forster, N., \& Johnsen, M. (1996). Expatriate management policies in UK companies new to the international scene. International Journal of Human Resource Management, 7, 179-205.

Froese, F. J. (2012). Motivation and adjustment of self-initiated expatriates: The case of expatriate academics in South Korea. International Journal of Human Resource Management, 23, 1095-1112.

Geddie, K. (2013). The transnational ties that bind: Relationship considerations for graduating international science and engineering research students. Population, Space, and Place, 19, 196-208.

Gerhardt, M. W., \& Brown, K. G. (2006). Individual differences in self-efficacy development: The effects of goal orientation and affectivity. Learning and Individual Differences, 16, 43-59.

Gianni, M., \& Tharenou, P. (2000). A cross-cultural study of the willingness of graduating students to accept expatriate assignments. In R. Edwards, C. Nyland, \& M. Coulthard, 
(Eds.), Readings in international business (pp. 337-360). Maryborough, Australia: Prentice Hall.

Glasman, L. R., \& Albarracin, D. (2006). Forming attitudes that predict future behavior: A meta-analysis of the attitude-behavior relation. Psychological Bulletin, 132, 778-822.

Grunert, M. L., \& Bodner, G. M. (2011). Finding fulfilment: Women's self-efficacy beliefs and career choices in chemistry. Chemistry Education Research and Practice, 12, 420-426.

Gungor, N. D., \& Tansel, A. (2008). Brain drain from Turkey: The case of professionals abroad. International Journal of Manpower, 29, 323-347.

Guo, S. B., \& Chase M. (2011). Internationalisation of higher education: Integrating international students into Canadian academic environment. Teaching in Higher Education, 16, 305-318.

Hair, J. F., Anderson, R. E., Tatham, R. L., \& Black, W. C. (1998). Multivariate data analysis (5th ed.). Englewood Cliffs, NJ: Prentice-Hall.

Harrison, D. A., Shaffer, M. A., \& Bhaskar-Shrinivas, P. (2004). Going places. Research in Personnel and Human Resources Management, 23, 199-247.

Henning, M. A., Krageloh, C., Moir, F., Doherty, I., \& Hawken, S. J. (2012). Quality of life of international and domestic students studying medicine in New Zealand. Perspectives on Medical Education, 1, 129-142.

Haslberger, A., Brewster, C., \& Hippler, T. (2013). The dimensions of expatriate adjustment. Human Resource Management, 52, 333-351. 
Institute of International Education (2013). Open doors data. International students: Academic level. Retrieved from http://www.iie.org/Research-and-Publications/Open-Doors/Data/International-Students/Ac ademic-Level/2011-13

Kim, H. Y. (2011). International graduate students' difficulties: graduate classes as a community of practices. Teaching in Higher Education, 16, 281-292.

Kline R. B., (2005). Principles and practice of structural equation modeling, New York: Guilford Press.

Konopaske, R., Robie, C., \& Ivancevich, J. M. (2005). A preliminary model of spouse influence on managerial global assignment willingness. International Journal of Human Resource Management, 16, 405-426.

Kraus, S. J. (1995). Attitudes and the prediction of behavior: A meta-analysis of the empirical literature. Personality and Social Psychology Bulletin, 21, 58-75.

Lee, E. (1966). A theory of migration. Demography, 3, 44-57.

Lee, C-S, \& Chao, C-W. (2013). Intention to "leave" or "stay" - The role of internship organization in the improvement of hospitality students' industry employment intentions. Asia Pacific Journal of Tourism Research, 18, 749-765.

Lent, R. W., Brown, S. D., \& Hackett, G. (1994). Toward a unifying social cognitive theory of career and academic interest, choice and performance. Journal of Vocational Behavior, 45, 79-122. 
Lent, R. W., Brown, S. D., \& Hackett, G. (1996). Career development from a social cognitive perspective. In D. Brown, \& L. Brooks (Eds.), Career choice and development ( $3^{\text {rd }}$ ed., pp. 373-421). San Francisco: Jossey-Bass.

Lent, R. W., Brown, S. D., \& Hackett, G. (2000). Contextual supports and barriers to career choice: A social cognitive analysis. Journal of Counseling Psychology, 47, 36-49.

Lent, R. W., Brown, S. D., Sheu, H. B., Schmidt, J., Brenner, B. R., \& Gloster, C. S. (2005). Social cognitive predictors of academic interests and goals in engineering: Utility for women and students at historically black universities. Journal of Counseling Psychology, $52,84-92$.

Mosneaga, A., \& Winther, L. (2013). Emerging talents? International students before and after their career start in Denmark. Population, Space, and Place, 19, 181-195.

OECD-UNDESA (2013). World migration in figures. Paris: OECD-UNDESA.

Oosterbeek, H., \& Webbink, D. (2011). Does studying abroad induce a brain drain? Economica, 78, 347-366.

Peltokorpi, V., \& Froese, F. J. (2009). Organizational expatriates and self-initiated expatriates: Who adjusts better to work and life in Japan? International Journal of Human Resource Management, 20, 1096-1112.

Podsakoff, P. M., MacKenzie, S. B., Lee, J-Y, \& Podsakoff, N. P. (2003). Common method biases in behavioral research: A critical review of the literature and recommended remedies. Journal of Applied Psychology, 88, 879-903. 
Ravenstein, R. G. (1889). The laws of migration. Journal of the Statistical Society of London, 52, 241-305.

Rottinghaus, P. J., Larson, L. M., \& Borgen, F. H. (2003). The relation of self-efficacy and interests: A meta-analysis of 60 samples. Journal of Vocational Behavior, 62, 221-236.

Rowthorn, R. (2008). The fiscal impact of immigration on the advanced economies. Oxford Review of Economic Policy, 24, 561-581.

Sabharwal, M. (2011). High-skilled immigrants: How satisfied are foreign-born scientists and engineers employed at American universities? Review of Public Personnel Administration, $31,143-170$.

Scholz, U., Sniehotta, F. F., Schuz, B., \& Oeberst, A. (2007). Dynamics of self-regulation: Plan execution self-efficacy and mastery of action plans. Journal of Applied Social Psychology, $37,2706-2725$.

Selmer, J., \& Lauring, J. (2011). Acquired demographics and reasons to relocate among self-initiated expatriates. International Journal of Human Resource Management, 22, 2055-2070.

Shaffer, M. A., Kraimer, M. L., Chen, Y-P, \& Bolino, M. C. (2012). Choices, challenges, and career consequences of global work experiences: A review and future agenda. Journal of Management, 38, 1282-1327.

Sherry, M., Thomas, P., \& Chui, W. H. (2010). International students: A vulnerable student population. Higher Education, 60, 33-46. 
Sheu, H-B, Lent, R. W., Brown, S. D., Miller, M. J., Hennessy, K. D., \& Duffy, R. D. (2010). Testing the choice model of social cognitive career theory across Holland themes: A meta-analytic path analysis. Journal of Vocational Behavior, 76, 252-264.

Spector, P. E. (1994). Using self-report questionnaires in OB research: A comment on the use of a controversial method. Journal of Organizational Behavior, 15, 385-392.

Spector, P. E. (2006). Method variance in organizational research: Truth or urban legend? Organizational Research Methods, 9, 221-232.

Soon, J-J. (2012). Home is where the heart is? Factors determining international students' destination country upon completion of studies abroad. Journal of Ethnic and Migration Studies, 38, 147-162.

Sutton, S. (1998). Predicting and explaining intentions and behaviour: How well are we doing? Journal of Applied Social Psychology, 28, 1317-1338.

Suutari, V., \& Brewster, C. (2000). Making their own way: International experience through self-initiated foreign assignments. Journal of World Business, 35, 417-436.

Suutari, V., Tornikoski, C., \& Makela, L. (2012). Career decision making of global careerists. International Journal of Human Resource Management, 23, 3455-3478.

Tharenou, P. (2003). The initial development of receptivity to working abroad: Self-initiated international work opportunities in young graduate employees. Journal of Occupational and Organizational Psychology, 76, 489-515. 
Tharenou, P. (2008). Disruptive decisions to leave home: Gender and family differences in expatriation choices. Organizational Behavior and Human Decision Processes, 105, 183-200.

UK Council for International Student Affairs (2014). International student statistics: UK higher education: Retrieved from http://www.ukcisa.org.uk/Info-for-universities-colleges--schools/Policy-research--statistics/ Research--statistics/International-students-in-UK-HE/\#International-(non-UK)-students-inUK-HE-in-2012-13

Vance, C. M. (2005). The personal quest for building global competence: A taxonomy of self-initiating career path strategies for gaining business abroad. Journal of World Business, 40, 374-385.

Vroom, V. (1964). Work and motivation. New York: Wiley.

Wang, B. C. Y., \& Bu, N. (2004). Attitudes toward international careers among male and female Canadian business students after 9-11. Career Development International, 9, 647-672.

Waung, M., Macneil, M., \& Vance, R. J. (1995). Reactions to feedback in goal choice and goal change processes. Journal of Applied Social Psychology, 25, 1360-1390.

Weber, M., Ruch, W., Littman-Ovadia, H., Lavy, S., \& Gai, O. (2013). Relationships among higher-order strengths factors, subjective well-being, and general self-efficacy: The case of Israeli adolescents. Personality and Individual Differences, 55,322-327. 
Weiss, D., Freund, A. M., \& Wiese, B. S. (2012). Mastering developmental transitions in young and middle adulthood: The interplay of openness to experience and traditional gender ideology on women's self-efficacy and subjective well-being. Development Psychology, 48, $1774-1784$.

Willard, G., \& Gramzow, R. H. (2009). Beyond oversights, lies, and pies in the sky: Exaggeration as goal-protection. Personality and Social Psychology Bulletin, 35, 497-492.

Workpermit.com (2012). Highly skilled migrant programme (HSMP). Retrieved from http://www.workpermit.com/uk/highly_skilled_migrant_program.htm 


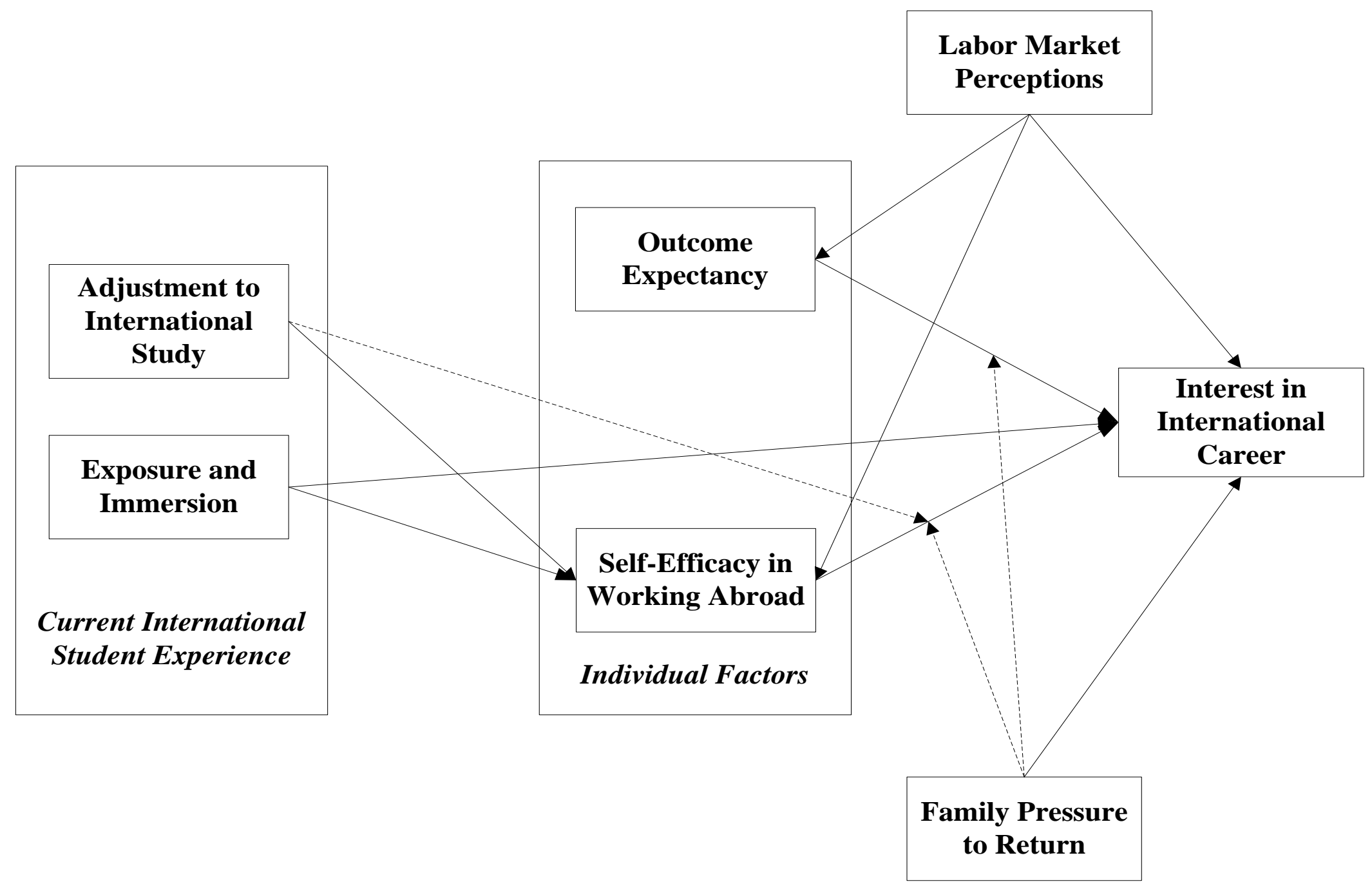

Figure 1.

The model that depicts the hypothesized links.

Note. Dotted lines represent moderating relationships. 
Table 1

Descriptive Statistics and intercorrelations $(N=139)$

\begin{tabular}{|c|c|c|c|c|c|c|c|c|c|c|c|c|c|}
\hline Variable & Mean & $S D$ & 1 & 2 & 3 & 4 & 5 & 6 & 7 & 8 & 9 & 10 & 11 \\
\hline 1. Age & 27.58 & 3.44 & - & & & & & & & & & & \\
\hline 2. Length of work experience & 3.25 & 2.91 & .72 & - & & & & & & & & & \\
\hline $\begin{array}{l}\text { 3. Length of international } \\
\text { work experience }\end{array}$ & .39 & .99 & .25 & .36 & - & & & & & & & & \\
\hline 4. Foreign labor market & 4.25 & 1.42 & .05 & -.02 & .26 & - & & & & & & & \\
\hline 5. Domestic labor market & 4.68 & 1.17 & -.11 & .04 & -.13 & -.15 & - & & & & & & \\
\hline 6. Family pressure to return & 4.69 & 1.47 & .10 & -.05 & -.34 & -.29 & -.05 & - & & & & & \\
\hline 7. Adjustment & 4.94 & .99 & .07 & .08 & 0 & .04 & .21 & .06 & - & & & & \\
\hline 8. Exposure and immersion & 3.71 & 1.03 & .26 & .33 & .25 & .17 & .12 & -.07 & .48 & - & & & \\
\hline 9. Self-efficacy & $71.39 \%$ & $12.90 \%$ & .09 & .14 & .15 & .22 & .03 & -.06 & .40 & .52 & - & & \\
\hline $\begin{array}{l}\text { 10. Outcome expectancy } \\
\text { (instrumentality x valence) }\end{array}$ & $54.71 \%$ & $16.19 \%$ & .06 & -.08 & -.01 & .13 & .07 & .27 & .24 & .23 & .35 & - & \\
\hline 11. Interest & 5.17 & 1.14 & .01 & -.08 & .12 & .24 & .05 & -.07 & .18 & .30 & .37 & .41 & - \\
\hline
\end{tabular}

Note. Coefficients $\geq|.17|,|.22|$ and $|.27|$ are significant at $.05, .01$ and .001 , respectively. 


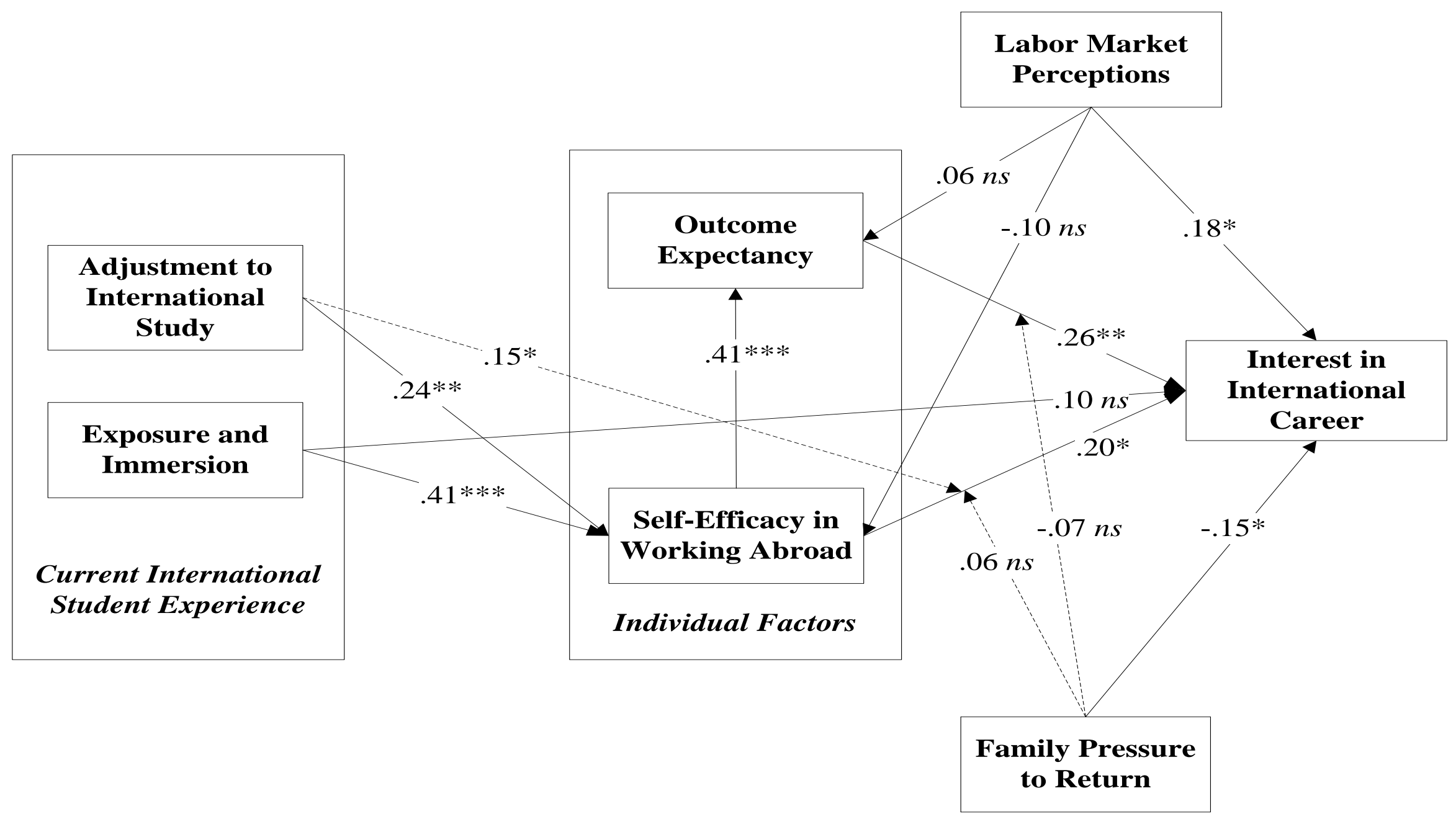

Figure 2.

The final causal-path model.

Notes. For reasons of simplicity, the control variables and error variances are not shown in this path diagram. Standardized parameter estimates are reported. Satorra-Bentler scaled $\chi^{2}(87, N=139)=95.5, p>.10 ; \mathrm{CFI}=.976 ; \mathrm{IFI}=.980 ; \mathrm{RMSEA}=.027 . * p<.05, * * p<.01, * * * p<.001$ 


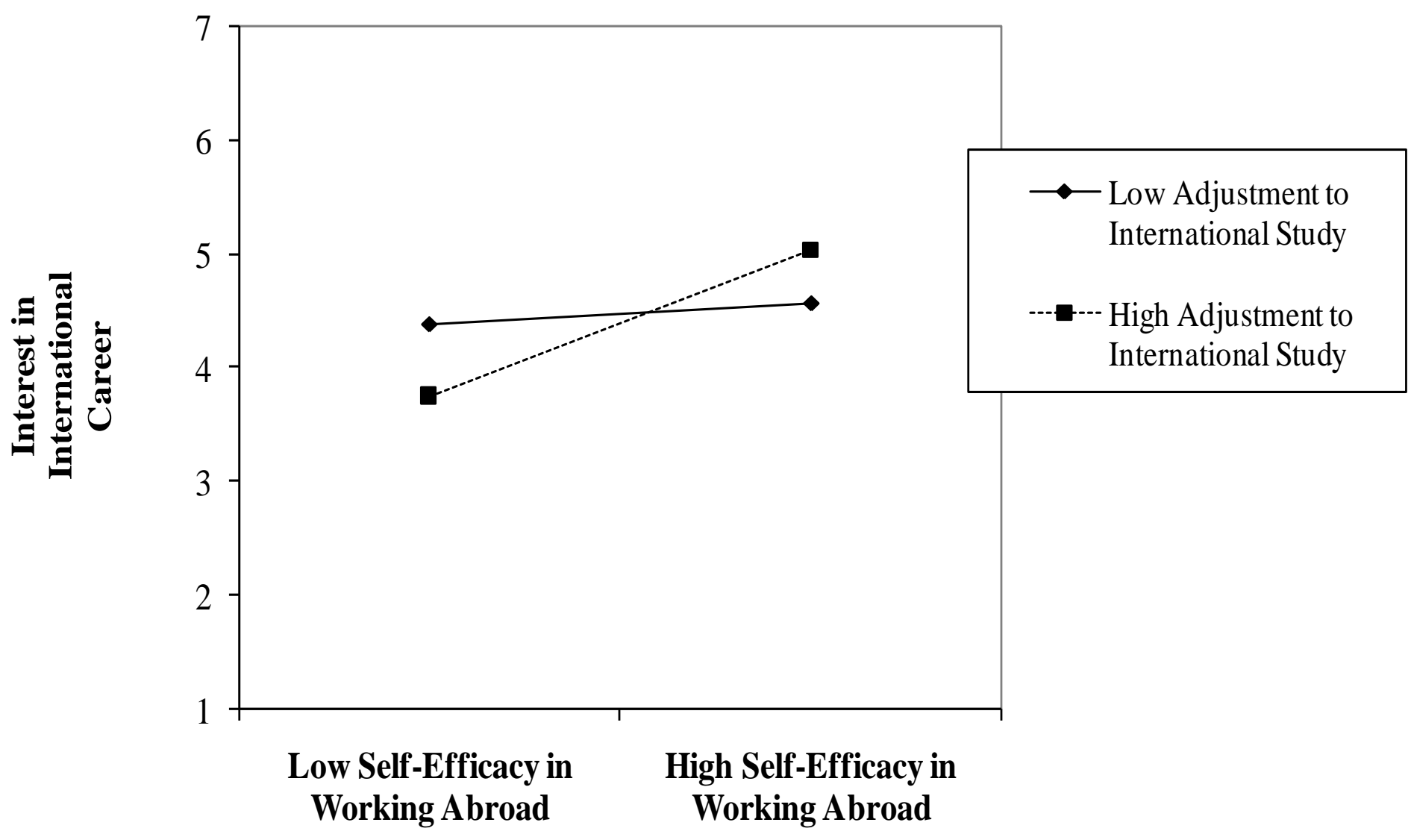

Figure 3.

The moderating effect of adjustment on the relationship of self-efficacy with interest. 


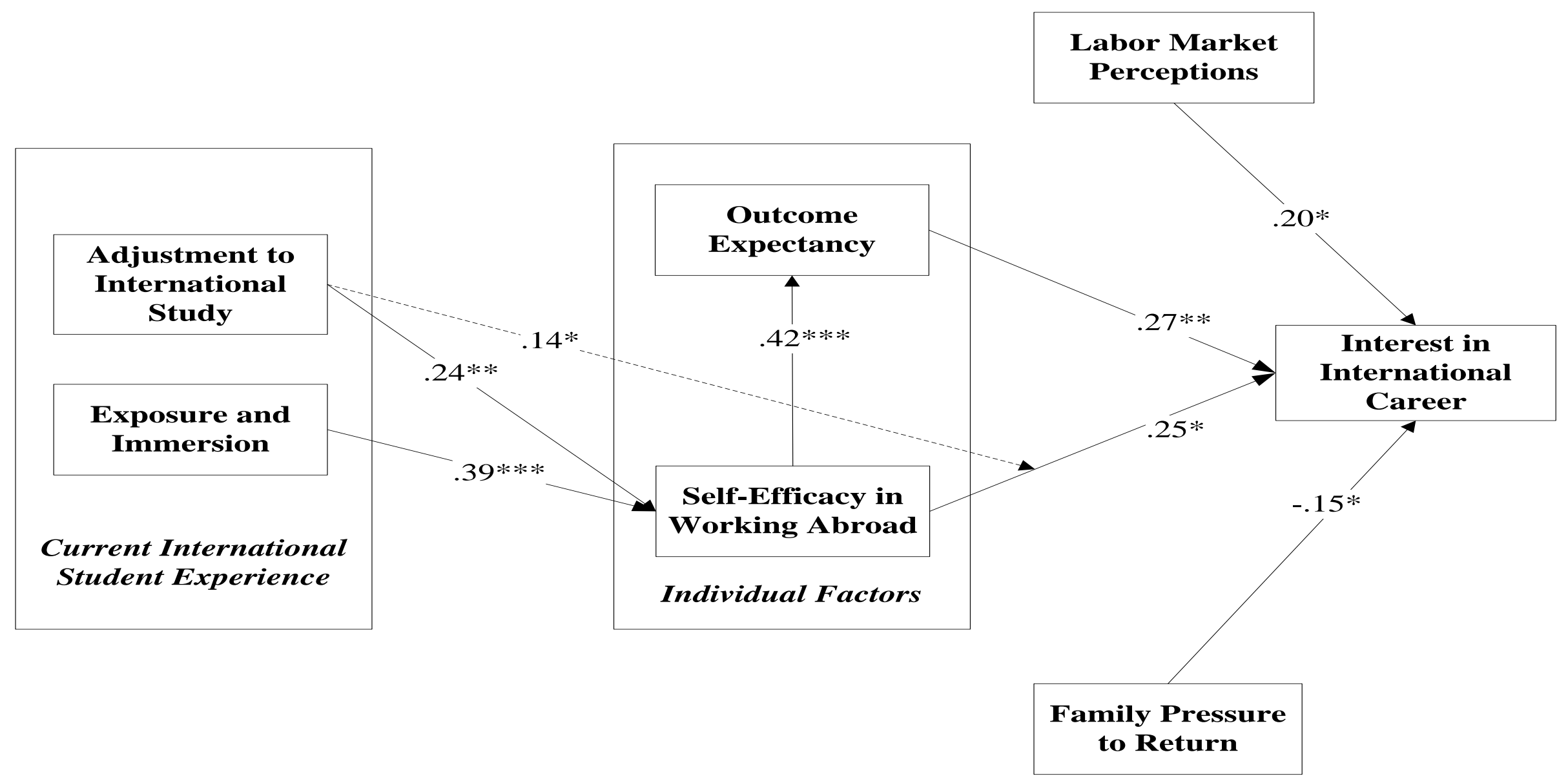

Figure 4.

The final causal-path model that includes only significant paths.

Notes. For reasons of simplicity, the control variables and error variances are not shown in this path diagram. Standardized parameter estimates are reported.

Satorra-Bentler scaled $\chi^{2}(58, N=139)=61.6, p>.10 ; \mathrm{CFI}=.990 ; \mathrm{IFI}=.992 ; \mathrm{RMSEA}=.021 . * p<.05, * * p<.01, * * * p<.001$ 